American Journal of

Health, Medicine and Nursing Practice (AJHMN)

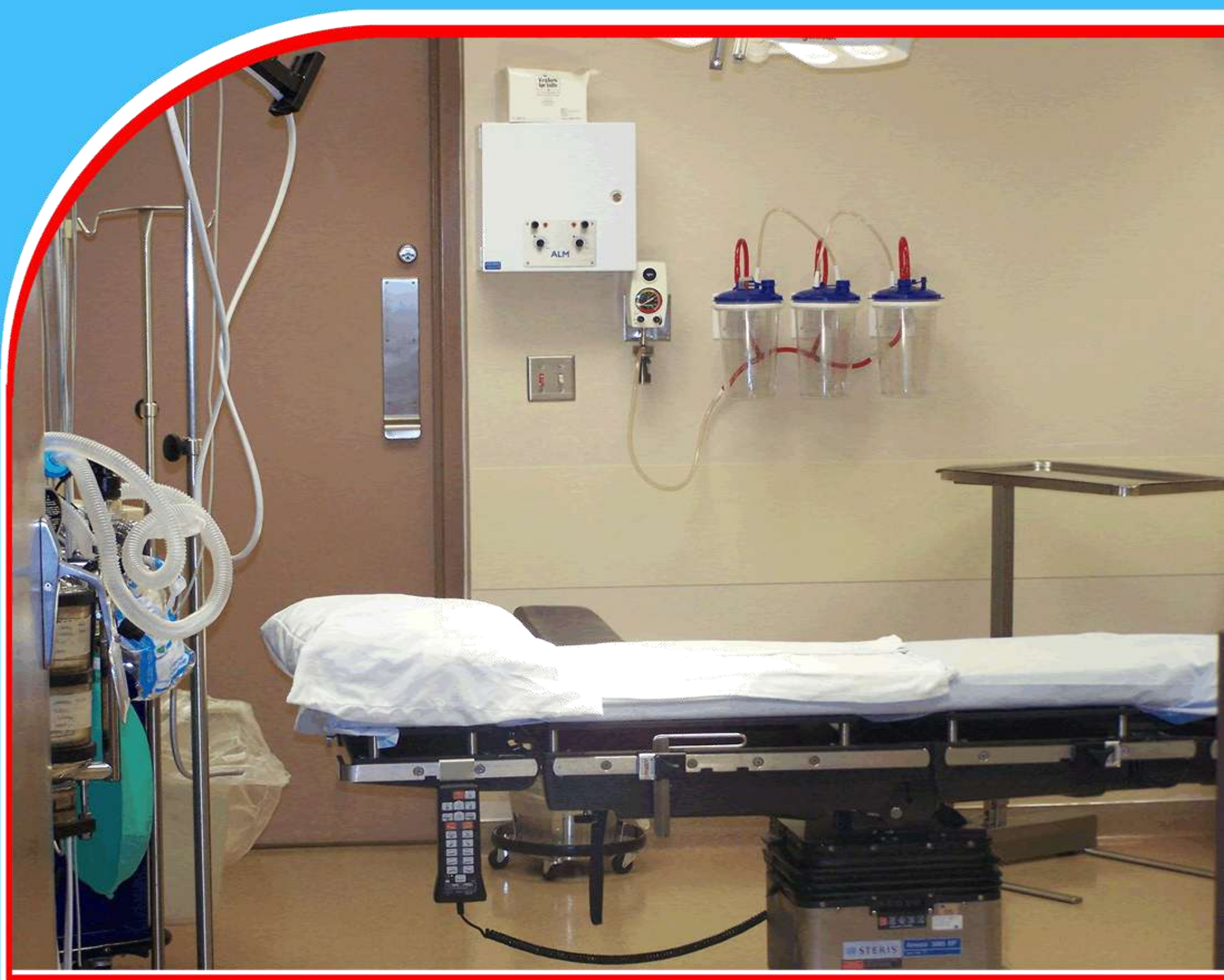

PRECONCEPTION CARE: AWARENESS, KNOWLEDGE, ATTITUDE AND PRACTICE OF PREGNANT WOMEN, TAMALE WEST HOSPITAL

AKWASI BOAKYE-YIADOM ESTHER SAGRU-LARR EMELIA ODURO

OBED KWAKU DUAH ASUMADU JOEL AFRAM SAAH RICHARD OPOKU ASARE

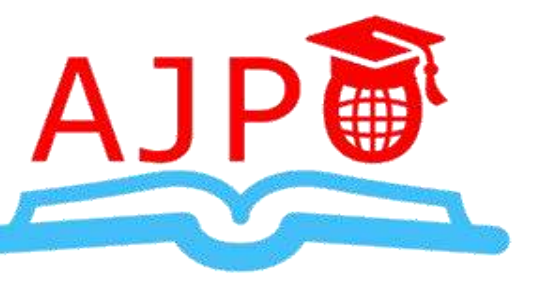




\title{
PRECONCEPTION CARE: AWARENESS, KNOWLEDGE, ATTITUDE AND PRACTICE OF PREGNANT WOMEN, TAMALE WEST HOSPITAL
}

\author{
AKWASI BOAKYE-YIADOM (MSc, B.Ed) ${ }^{1}$ \\ Department of Public Health, School of Allied Health Sciences \\ University for Development Studies, Tamale, Ghana \\ ESTHER SAGRU-LARR (BSc. Midwifery) ${ }^{2}$ \\ Department of Midwifery, School of Allied Health Sciences \\ University for Development Studies, Tamale, Ghana \\ EMELIA ODURO (BSc. Midwifery) ${ }^{3}$ \\ Department of Midwifery, School of Allied Health Sciences \\ University for Development Studies, Tamale, Ghana \\ OBED KWAKU DUAH ASUMADU (BSc. Nursing) ${ }^{4}$ \\ Department of Nursing, School of Allied Health Sciences \\ University for Development Studies, Tamale, Ghana \\ JOEL AFRAM SAAH (B.Ed. Health Science) ${ }^{5}$ \\ Department of Public Health, School of Allied Health Sciences \\ University for Development Studies, Tamale, Ghana \\ *RICHARD OPOKU ASARE (MPhil, B.Ed, RN (Dip)-RMN, Cert.Ed.) ${ }^{6}$ \\ College of Nursing, Ntotroso \\ Ahafo Region, Ghana. \\ Corresponding Author's Email: asareor@gmail.com
}




\section{ABSTRACT}

Purpose: The aim was to assess the awareness, attitude, knowledge level and practice of pregnant women on preconception care at the Tamale West Hospital Antenatal clinic in the Northern region of Ghana.

Methodology: This study used a descriptive cross-sectional design with a quantitative approach. A quota sampling procedure was used to arrive at 200 participants. The starting point was randomly selected and a systematic random sampling method was used to select the study participants. Simple random sampling using the lottery approach was used to select the participants for the study. The target population was women (literate and illiterate) within the age range of 16 and 40 years attending the Tamale West Hospital for antenatal care. The list of all the women who fell within the target population was obtained from the register of the unit. The inclusion criteria were pregnant women who visited the Tamale West Hospital within a month's duration for antenatal care services. A semi-structured questionnaire which had both open-ended and closeended questions was used to generate the data. Descriptive statistics which involves frequencies and percentages was used to represent both independent and dependent variables of the study. Close-ended responses were inputted using the Microsoft Office Excel 2016. Open-ended responses were compiled in relation to the objectives of the study. Other relevant outcomes were cross-tabulated using SPSS version 21.

Results: Though $20.0 \%$ of the pregnant women had positive attitude towards preconception care, only $34.5 \%$ were aware of preconception care and $42.5 \%$ and $23.5 \%$ had poor and high knowledge levels on preconception care respectively. When the age group was cross-tabulated with awareness, the results showed no statistical significance between the two variables $\left(\chi^{2}=9.1\right.$; $\mathrm{p}=0.58)$. However, there was an association between the educational status (Tertiary level) $\left(\chi^{2}=49.6 ; \mathrm{p}=0.01\right)$ and religious affiliation (Muslim) $\left(\chi^{2}=43.3 ; \mathrm{p}=0.01\right)$ of the respondents on awareness. Educational status (Tertiary level) $\left(\chi^{2}=45.4 ; \mathrm{p}=0.01\right)$ and religion $(\chi 2=21.3 ; \mathrm{p}=0.01)$ were found to influence knowledge statistically. In terms of overall attitude, only Muslim $\left(\chi^{2}=4.12\right.$; $\mathrm{p}=0.04$ ) statistically impacted on the study.

Conclusion: Pregnant women who attend Antenatal clinic at Tamale West Hospital tended to have low level of awareness and poor knowledge, they have negative attitude towards preconception care services and seldom practice preconception care. There is the need for health care authorities to intensify awareness and implement preconception care policies.

Recommendation: The present study demonstrated that there was a need to create awareness which can also increase the knowledge and practices of reproductive age women or couples. Hence, there is the need for health authorities to put together comprehensive preconception care policies for health institutions to abide by.

Key words: Preconception, Awareness, Knowledge, Attitude, Practice, Tamale 
American Journal of Health, Medicine and Nursing Practice

ISSN 2520-4017 (Online)

Vol.5, Issue 1 No.5, pp 66 - 83, 2020

www.ajpojournals.org

\section{INTRODUCTION}

Preconception cares are interventions that are provided to women or couples prior to conception. As it is important for every woman to attend the antenatal clinic during pregnancy, so is it important for them (including their partners), to patronize preconception care before they decide to conceive.

Every woman deserves good health in mind and body especially before, during and after birth. This also goes for the babies they deliver; hence, giving birth to preconception care. Preconception care provides biomedical, behavioral and social health interventions to women and couples before conception occurs. ${ }^{[1]}$ It consists of preventive, promotive or curative health and social interventions before pregnancy occurs. It is also seen as the period between 3 months before conception to 3 months after conception. ${ }^{[2]}$ It is defined as any intervention provided to women of childbearing age, regardless of their pregnancy status or desire before pregnancy, to improve health outcomes for women, newborns and children. It is a very important aspect of maternal health care which has been neglected over the years especially in developing countries. ${ }^{[3]}$

In countries, such as Canada, the United Kingdom, Spain, Australia, Hungry and the Netherlands, where preconception cares (PCC) are available and patronized, it is seen that there has been improvement in the health of women and also reduction of pregnancy related complications as well as abnormalities affecting newborns during and after pregnancy. Even if preconception care aims primarily at improving maternal and child health, it brings health benefits to adolescents, women and men, irrespective of their plans to become parents. ${ }^{[1]}$ Also, the benefit of preconception care is the improvement of public health which is achieved by improving individual health. ${ }^{[4]}$ Preconception care is highly associated with increasing antenatal care, delivery care and post-natal care service utilizations which are the corner stones to improve maternal and child health. Unfortunately, a study conducted on maternal and child health in sub-Saharan Africa in 2011 reported that preconception care is poorly practiced due to inadequate health care workers, unstable financial standing, illiteracy and lack of awareness on the subject matter ${ }^{[5]}$ Regrettably, these social and personal factors have made implementing and practicing preconception care very unstable and inconsistent even for countries which have facilities that provide preconception services.

A study discovered that $63.5 \%$ of the participants were aware of preconception care and their source of information being the antenatal clinics, whereas $54.7 \%$ of them claimed to be aware of folic acid supplementation and also to avoid certain lifestyles like smoking and alcohol before pregnancy. ${ }^{[2]}$ It is important for women of childbearing age to consume vitamins containing folic acid to get the daily requirement of 400 micrograms. ${ }^{[6]}$ Another study also found that $55.9 \%$ of their respondents were aware of preconception care, and most of the respondents constituting $90.30 \%$ mentioned promoting health as the components of preconception care. ${ }^{[7]}$ More so, it was reported in a study that $31.8 \%$ of their sample size were aware of preconception care with the major source of information coming from the health institution, and friends and the mass media as the minority sources. ${ }^{[8]}$ Additionally, it was reported that $35.5 \%$ of the participants were aware of preconception care and majority also agreed that preconception care is important. ${ }^{[4]}$ These findings were much higher than that of a report which had $11.0 \%$ awareness level. ${ }^{[9]}$ However, it is 
documented in other studies that women were more aware of certain preconception care topics than men. ${ }^{[10,11]}$

A research conducted in low-income Mexican-American population revealed that $80 \%$ of the respondents had knowledge on preconception care (they agreed that improved preconception care benefits pregnancy). They also had high knowledge certain facts; the benefits or disadvantages of the use of folic acid, the use of alcohol; verbal, physical and sexual abuse. ${ }^{[12]}$ A study has it that majority of the participants took folic acid before pregnancy or within the first trimester of their pregnancy. ${ }^{[13]}$ Notwithstanding, other reports have documented relatively poor knowledge levels among their participants. ${ }^{[14,15]}$

A similar research found that $15.5 \%$ of the respondents had adequate knowledge of preconception care, $64.5 \%$ of the respondents had moderate knowledge and $20 \%$ of respondents had inadequate knowledge regarding preconception care. This is a clear indication that practice of preconception care might be low or not practiced at all. ${ }^{[16]}$ Another study conducted in Iran reported a moderate knowledge level of preconception care among 30-67\% of healthcare providers. According to the report, providers with poor knowledge of PCC were $11.7 \% .{ }^{[17]}$

Generally, studies have shown that nurses and health care workers have a positive attitude towards preconception care, but there is lack of implementation. ${ }^{[18,19]}$ An Iranian cross-sectional study among midwives revealed that their attitude score was good. ${ }^{[20]}$ Most studies have also shown that respondents with knowledge on preconception care believe that it is an important part of maternal and child health care. However, a study conducted on adolescent girls showed that $96.7 \%$ of them had unfavorable attitude towards preconception care, $3.30 \%$ had moderate attitude, and none had favorable attitude during the pre-test level; whereas all the respondents (100\%) had favorable attitude during the post-test. ${ }^{[16]}$

Current researches have shown that most women are unaware of their pregnancy status until several weeks have passed; hence exposing the fetus to unhealthy risks and this can be a factor why most women do not show positive attitude towards preconception care. ${ }^{[12]}$ More so, worldwide statistics showed that few people have an idea on preconception care but most of them have moderate or no knowledge on preconception care. However, it is not certain whether this knowledge motivates people to practice or patronize preconception care. There is reason to believe that the knowledge and awareness level of people with regards to preconception care (PCC) is directly proportional to their practice or patronize level. It is revealed in a study that $65.9 \%$ of respondents had never practiced preconception care or never sought the services. Besides, those who had ever practiced preconception care (less than 35\%) had heard it from their antenatal sessions at the clinic when they were already pregnant. This then emphasizes the theory that most, if not all of them, never practiced preconception care before their first conception or pregnancy. ${ }^{[2]}$ However, it is established that there are poor preconceptional practices. ${ }^{[14]}$

In Ghana, there is lack of awareness of this kind of care, not to talk of the patronage of this care. Even those who are aware of the preconception care, due to reasons or factors like inadequate resources, time and health facilities are not able to patronize the services of preconception care. Most women due to the cultural nature of the people in the Tamale Metropolis do not have a say 
especially when it comes to their sexual life. The culture which puts the man in charge, therefore makes it difficult for most women (especially those with low or no educational background and even some educated women) to suggest things like the number of children or when they would like to have kids. This is because they believe that "it is ok for a man to produce lots of offspring without being rich". Also, these women who probably have rivals would be interested in giving birth to more children for their husbands or partner without caring about the health consequences. These have caused most women to give birth between 8 and 10 children. It is also noted that most of the hospitals and clinics in the Tamale Metropolis do not have units where preconception care services are rendered. Preconception care is not regularly given to all women in the general population and for that matter they are exposed to drinking of alcohol, smoking, drug use, and lack access to folic acid supplementation unless they are recognized to have risk factors. ${ }^{[21]}$ Because there is minimal information on pregnant women on preconception care in Ghana, this study aimed to assess the awareness, knowledge, attitude and practice of pregnant women attending antenatal clinic (ANC) at the Tamale West Hospital.

\section{METHODOLOGY}

This was a descriptive cross-sectional study using a quantitative approach on awareness, knowledge, attitudes and practices among women attending antenatal clinic at the Tamale West Hospital on their preconception care. Inclusion criteria were pregnant women who attended ANC at Tamale West Hospital within a month's duration.

The researchers conducted the study on a quota of 200 respondents. The starting point was randomly selected and a systematic random sampling method was used to select the study participants. Simple random sampling using the lottery approach was used to select the participants for the study. The target population was women (literate and illiterate) within the age range of 16 and 40 years attending the Tamale West Hospital for antenatal care. The list of all the women who fell within the target population was obtained from the register of the unit.

Data for the study was collected using a semi-structured questionnaire which had both open-ended and close-ended questions; subdivided into six sections. Section one comprised the sociodemographic characteristics which include age, gender, religion, occupation, marital status and educational levels of the respondents. The second section was associated with the past obstetric history of the participants which has the following questions: number of pregnancies, number of children; patronage of a health facility before conception and the utilization of antenatal services during previous pregnancies. Section three consisted of three questions to assess the level of awareness of respondents on preconception care. The fourth section comprised questions to assess the level of knowledge of the participants. The fifth section is characterized by "yes" or "no" questions on the level of patronage, and the sixth section included questions to assess their attitude towards preconception care.

Descriptive statistics which involves frequencies and percentages were used in representing data for the socio-demographic characteristics of all respondents. Data analysis was done systematically using a quantitative study approach. Data was imputed using the Microsoft Office Excel 2016. The entry sheets were designed with appropriate definitions and codes to help 
minimize errors during data entry. Open ended questions on the questionnaire which were supposed to yield qualitative data were compiled in relation to the set aims and objectives of the study. Besides, responses on other items and other relevant questions were cross-tabulated. The close ended data were analyzed using Statistical Package for Social Sciences (SPSS) version 21.

\section{RESULTS}

\section{Socio-demographic characteristics}

All 200 questionnaires administered merited inclusion for analysis. Majority of the pregnant women $75(37.5 \%)$ were between the ages 21 and 25 years. The highest were married $183(91.5 \%)$ with educational status as tertiary being $62(31.0 \%)$ of the respondents. In terms of religious sects, the Muslims 157 (78.5\%) were the majority with none (0.0\%) practicing the African Traditional Religion. However, more than half of the respondents were self-employed 111 (55.5\%) when it comes to their occupational status.

On the obstetric history of the participants for the study, a total number of $60.5 \%(\mathrm{~N}=200)$ stated "yes" that it was not their first pregnancy. A greater number of the respondents $(62.5 \%)$ claimed to have planned for the pregnancies they carried. Remarkably, in the interviews with respondents, $60.0 \%$ of them said: "there is no reason whatsoever, they just didn't go to the health facility".

Almost all of the respondents $(60.0 \%)$ had attended ANC during other pregnancies. For those whose partners were not able to accompany them gave reasons like; "my husband was not around then", "because of his work, he hardly has time.", and interestingly some of them gave "my husband just refused to come with me for no good reason" as the reason even though the respondents insisted on it. Table 1 depicts the socio-demographic data of the respondents. 
Table 1: Socio-demographic characteristics $(\mathrm{N}=\mathbf{2 0 0})$

\begin{tabular}{|c|c|c|}
\hline Background information & $\mathbf{N}$ & $(\%)$ \\
\hline \multicolumn{3}{|l|}{ Age } \\
\hline $16-20$ & 25 & $12.5 \%$ \\
\hline $21-25$ & 75 & $37.5 \%$ \\
\hline $26-30$ & 64 & $32.0 \%$ \\
\hline $31-35$ & 20 & $10.0 \%$ \\
\hline $36-40$ & 16 & $8.0 \%$ \\
\hline \multicolumn{3}{|l|}{ Marital status } \\
\hline Single & 16 & $8.0 \%$ \\
\hline Married & 183 & $91.5 \%$ \\
\hline Divorced & 1 & $0.5 \%$ \\
\hline \multicolumn{3}{|l|}{ Educational level } \\
\hline Nil & 22 & $11.0 \%$ \\
\hline Primary & 17 & $8.5 \%$ \\
\hline Junior high & 48 & $24.0 \%$ \\
\hline Senior high & 51 & $25.5 \%$ \\
\hline Tertiary & 62 & $31.0 \%$ \\
\hline \multicolumn{3}{|l|}{ Religious affiliation } \\
\hline Christianity & 43 & $21.5 \%$ \\
\hline Muslim & 157 & $78.5 \%$ \\
\hline African Traditionalist & 0 & $0.0 \%$ \\
\hline \multicolumn{3}{|l|}{ Occupation } \\
\hline Unemployed & 24 & $12.0 \%$ \\
\hline Students & 25 & $12.5 \%$ \\
\hline Self-employed & 111 & $55.5 \%$ \\
\hline Formal salary earner & 40 & $20.0 \%$ \\
\hline \multirow[t]{2}{*}{ Obstetric History } & \multicolumn{2}{|c|}{ Response Rate $(\mathrm{N}=200)$} \\
\hline & Yes $(\%)$ & No $(\%)$ \\
\hline First pregnancy & $79(39.5 \%)$ & $121(60.5 \%)$ \\
\hline Plan for pregnancy & $125(62.5 \%)$ & $75(37.5 \%)$ \\
\hline Visit to health facility & $75(37.5 \%)$ & $125(62.5 \%)$ \\
\hline Pre-existing medical condition & $44(22.0 \%)$ & $156(78.0 \%)$ \\
\hline Screened & $70(35.0 \%)$ & $130(65.0 \%)$ \\
\hline Attend ANC & $120(60.0 \%)$ & $80(40.0 \%)$ \\
\hline Went with partner & $70(35.0 \%)$ & $130(65.0 \%)$ \\
\hline \multirow{2}{*}{$\begin{array}{l}\text { How many times attended ANC } \\
\text { with partner? }\end{array}$} & \multicolumn{2}{|c|}{ Response Rate $(\mathrm{N}=\mathbf{2 0 0})$} \\
\hline & $1-5$ & 6-10 \\
\hline Response & $62(31.0 \%)$ & $138(69.0 \%)$ \\
\hline \multirow[t]{2}{*}{ Parity } & \multicolumn{2}{|c|}{ Number of Children } \\
\hline & $0-3$ & 4-6 \\
\hline Response & $191(95.5 \%)$ & $9(4.5 \%)$ \\
\hline \multirow[t]{2}{*}{ Number of ANC attendance } & \multicolumn{2}{|c|}{ Attendance Rate } \\
\hline & $1-6$ & $7-12$ \\
\hline Response & $43(21.5 \%)$ & $157(78.5 \%)$ \\
\hline
\end{tabular}

Source: Field data, 2019 


\section{Awareness of Preconception Care (PCC)}

When respondents were asked what they knew about PCC, $69(34.5 \%)$ of them claimed to have heard about preconception care with majority $65.5 \%(\mathrm{~N}=200)$ claiming unawareness of it. When those who responded in the affirmative were asked about their sources of information, the mass media recorded $7(3.50 \%)$, friends $6(3.00 \%)$, health worker $15(7.50 \%)$, and from the health facility $41(20.50 \%)$.

This shows that most of the pregnant women for this study were less aware of the availability of preconception care interventions/services for them.

\section{Knowledge of Respondents on PCC}

Respondents knowledge on PCC was further were assessed based on 10 questions from that section of the questionnaire. An operational definition was assigned to determine their scoring rates. A score of 0-3 correctly answered questions were deemed as having low knowledge; 4-6 as moderate knowledge; and 7-10 symbolized higher knowledge on preconception care.

However, observation from the table below shows that most of the respondents answered "no" to the questions that were asked indicating low level of knowledge. In view of this their overall knowledge was computed to assess their scoring rate. The overall findings on knowledge towards PCC are presented in Table 2 below where a higher percentage of respondents $42.5 \%(\mathrm{~N}=85 / 200)$ had poor knowledge whiles $34 \%$ had moderate knowledge and a lesser percentage of $23.5 \%$ has high knowledge on PCC. 
American Journal of Health, Medicine and Nursing Practice

ISSN 2520-4017 (Online)

Vol.5, Issue 1 No.5, pp 66 - 83, 2020

www.ajpojournals.org

Table 2: Responses on Knowledge of PCC

\begin{tabular}{lcc}
\hline Variables & \multicolumn{2}{c}{ Response Rate (N=200) } \\
\cline { 2 - 3 } & Yes (\%) & No (\%) \\
\hline $\begin{array}{l}\text { PCC is care given to women/couples prior to } \\
\text { pregnancy }\end{array}$ & $122(61.0 \%)$ & $78(39.0 \%)$ \\
PCC can be patronized only during pregnancy & $56(28.0 \%)$ & $144(72.0 \%)$ \\
PCC ends at the beginning of pregnancy & $48(24.0 \%)$ & $152(76.0 \%)$ \\
Early detection and management of ill health & $110(55.0 \%)$ & $90(45.0 \%)$ \\
couples are some of services provided by PCC & & \\
PCC also provides preventive treatment & $113(56.5 \%)$ & $87(43.5 \%)$ \\
ANC is an extended part of PCC & $96(48.0 \%)$ & $104(52.0 \%)$ \\
PCC is not a neglected part of maternal and child & $57(28.5 \%)$ & $143(71.5 \%)$ \\
welfare & & $173(86.5 \%)$ \\
PCC is more important than ANC & $27(13.5 \%)$ & $137(68.5 \%)$ \\
Inter-conception care is part of PCC & $63(31.5 \%)$ & $138(69.0 \%)$ \\
Inter-conception care is PCC that is given in & $62(31.0 \%)$ & \\
between pregnancies & &
\end{tabular}

\begin{tabular}{lcc}
\multicolumn{4}{c}{ Overall Knowledge Score Rate $(\mathbf{N}=\mathbf{2 0 0})$} \\
\hline Knowledge & Score & N (\%) \\
\hline Poor knowledge & $0-3$ & $85(42.5 \%)$ \\
Moderate knowledge & $4-6$ & $68(34.0 \%)$ \\
High knowledge & $7-10$ & $47(23.5 \%)$ \\
\hline
\end{tabular}

Source: Field data, 2019

\section{Attitude of Respondents towards PCC}

Table 3 describes the attitude of respondents towards PCC. Observation from the table shows that $96(48.0 \%)$ of the respondents strongly agreed that it was very important for every woman to receive preconception care; and $4(2.0 \%)$ strongly disagreed with the view that preconception care was important in the reproductive years. A total of $171(85.5 \%)$ respondents gave support to private hospitals as the best for PCC whilst a total of 29 (14.5\%) respondents were against that view, which they were right. In view of this their overall attitude towards PCC was evaluated and categorised into positive and negative based on the score chalked on the correct or wrong answers they responded to on the items under the attitude. A score of seven or more correctly out of the 10 appropriate responses from the 25 scores were operationally labelled as having "positive" attitude; and those who had 11 or more from the 15 wrong answers were operationally categorised as having 
American Journal of Health, Medicine and Nursing Practice

ISSN 2520-4017 (Online)

Vol.5, Issue 1 No.5, pp 66 - 83, 2020

www.ajpojournals.org

"negative" attitude. The data finally showed that majority $160(80 \%)$ had negative attitude towards PCC. The Results are also shown in table below.

Table 3: Attitude towards PCC

\begin{tabular}{|c|c|c|c|}
\hline \multirow[t]{2}{*}{ Attitude } & & \multicolumn{2}{|c|}{ Response Rate $(\mathrm{N}=200)$} \\
\hline & & Correct $(\%)$ & Wrong (\%) \\
\hline \multicolumn{4}{|c|}{ PCC is important for every woman } \\
\hline Strongly agree & & $96(48.0 \%)$ & - \\
\hline Agree & & $60(30.0 \%)$ & - \\
\hline Neutral & & - & $22(11.0 \%)$ \\
\hline Disagree & & - & $18(9.0 \%)$ \\
\hline Strongly disagree & & - & $4(2.0 \%)$ \\
\hline Total & & $156(78.0 \%)$ & $44(22.0 \%)$ \\
\hline \multicolumn{4}{|c|}{ PCC is important during reproductive years } \\
\hline Strongly agree & & $51(25.5 \%)$ & - \\
\hline Agree & & $84(42.0 \%)$ & - \\
\hline Neutral & & - & $38(19.0 \%)$ \\
\hline Disagree & & - & $23(11.5 \%)$ \\
\hline Strongly disagree & & - & $4(2.0 \%)$ \\
\hline Total & & $135(67.5 \%)$ & $65(32.5 \%)$ \\
\hline \multicolumn{4}{|c|}{ PCC has implications on pregnancy and delivery } \\
\hline Strongly agree & & - & $37(18.5 \%)$ \\
\hline Agree & & - & $59(29.5 \%)$ \\
\hline Neutral & & - & $70(35.0 \%)$ \\
\hline Disagree & & $25(12.5 \%)$ & - \\
\hline Strongly disagree & & $9(4.5 \%)$ & - \\
\hline Total & & $34(17.0 \%)$ & $166(83.0 \%)$ \\
\hline \multicolumn{4}{|c|}{ Government hospitals are the best for PCC } \\
\hline Strongly agree & & $21(10.5 \%)$ & - \\
\hline Agree & & $74(37.0 \%)$ & - \\
\hline Neutral & & - & $36(18.0 \%)$ \\
\hline Disagree & & - & $52(26.0 \%)$ \\
\hline Strongly disagree & & - & $17(8.5 \%)$ \\
\hline Total & & $95(47.5 \%)$ & $105(52.5 \%)$ \\
\hline \multicolumn{4}{|c|}{ Private hospitals are the best for PCC } \\
\hline Strongly agree & & - & $61(30.5 \%)$ \\
\hline Agree & & - & $79(39.5 \%)$ \\
\hline Neutral & & - & $31(15.5 \%)$ \\
\hline Disagree & & $20(10.0 \%)$ & - \\
\hline Strongly disagree & & $9(4.5 \%)$ & - \\
\hline Total & & $29(14.5 \%)$ & $171(85.5 \%)$ \\
\hline \multicolumn{4}{|c|}{ Overall Attitude of Respondents } \\
\hline Attitude & Score & $\mathbf{N}$ & $\%$ \\
\hline Positive & 10 & 40 & 20.0 \\
\hline Negative & 15 & 160 & 80.0 \\
\hline Total & 25 & 200 & 100 \\
\hline
\end{tabular}

Source: Field data, 2019 


\section{Practices of Preconception Care (PCC)}

In order to assess the practices of the respondents, participants were asked as to what kind of preconception services they practiced or benefited from among other items. According to the data, majority $(85 \%)$ of the respondents had never patronized preconception care services and only a few $(15 \%)$ of them ever sought the services. Interestingly, majority $(56.5 \%)$ of the respondents said that there were no PCC units in Tamale with $43.5 \%$ accentuating to the statement that there is. Table 4 gives frequency distribution of the practices on PCC.

Table 4: Practices on preconception care

\begin{tabular}{|c|c|c|}
\hline \multirow[b]{2}{*}{ Variables } & \multicolumn{2}{|c|}{ Response Rate $(\mathrm{N}=200)$} \\
\hline & Yes $(\%)$ & No $(\%)$ \\
\hline Patronage of PCC services & $30(15 \%)$ & $170(85 \%)$ \\
\hline PCC Units in Tamale & $87(43.5 \%)$ & $113(56.5 \%)$ \\
\hline Are there PCC units in TWH & $25(12.5 \%)$ & $175(87.5 \%)$ \\
\hline Ever patronized PCC services? & $11(5.5 \%)$ & $189(94.5 \%)$ \\
\hline Was it helpful? & $10(5.5 \%)$ & $190(94.5 \%)$ \\
\hline Intention to continue seeking PCC services & $147(73.5)$ & $53(23.5 \%)$ \\
\hline \multicolumn{3}{|l|}{ Kind of practices } \\
\hline $\begin{array}{l}\text { - Do you undertake exercises within each } \\
\text { week? }\end{array}$ & $127(63.5 \%)$ & $73(36.5 \%)$ \\
\hline \multicolumn{3}{|l|}{ What kind of exercises do you do? } \\
\hline - Sweeping & $1(0.5 \%)$ & - \\
\hline - Walking & $177(88.5 \%)$ & - \\
\hline - Jogging & $13(6.5 \%)$ & - \\
\hline - Swimming & $2(1.0 \%$ & - \\
\hline - $\quad$ Skipping & $1(0.5 \%)$ & - \\
\hline - $\quad$ Squatting & $6(3.0 \%)$ & - \\
\hline Do you eat well before and during conception? & $156(78.0 \%)$ & $44(22.0 \%)$ \\
\hline \multicolumn{3}{|l|}{ How does your food look like often? } \\
\hline - Not balanced & $13(6.5 \%)$ & - \\
\hline - Semi-balanced & $83(41.5 \%)$ & - \\
\hline - Balanced-diet & $104(52.0 \%)$ & - \\
\hline Have you ever used folic acid before conception? & $68(34.0 \%)$ & $132(66.0 \%)$ \\
\hline Was it prescribed at a health facility? & $168(84.0 \%)$ & $32(16.0 \%)$ \\
\hline
\end{tabular}

Source: Field data, 2019 
American Journal of Health, Medicine and Nursing Practice

ISSN 2520-4017 (Online)

Vol.5, Issue 1 No.5, pp 66 - 83, 2020

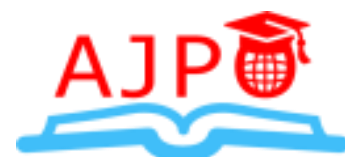

www.ajpojournals.org

\section{Bivariate Analyses of Independent and Dependent Variables}

\section{Socio-demographics and Awareness of PCC}

These analyses were carried out to see the strength of the independent variables as against the dependent variables to ascertain their statistical significance to the study. Though the age group of 21-25 had the highest number of participants being aware of PCC services, when it was cross-tabulated with awareness, results showed no statistical significance between the two variables $\left(\chi^{2}=9.1 ; p=0.58\right)$. More so, there was no association between the marital status and the level of awareness of the respondents as the p-value and significant difference showed. Besides, there was an association between the educational level (Primary level) $\left(\chi^{2}=49.6 ; p=0.01\right)$ and religious affiliation (Christianity) $\left(\chi^{2}=43.3 ; p=0.01\right)$ of the respondents. This is shown in table 5.

Table 5: Socio-demographics and Awareness of PCC

\begin{tabular}{|c|c|c|c|c|}
\hline \multirow[t]{2}{*}{ Variable } & \multicolumn{2}{|c|}{ Awareness of PCC } & \multirow[t]{2}{*}{$\chi^{2}$} & \multirow{2}{*}{$\begin{array}{c}\text { P- } \\
\text { value }\end{array}$} \\
\hline & Yes $(\%)$ & No $(\%)$ & & \\
\hline \multicolumn{5}{|l|}{ Age group } \\
\hline $16-20$ & $4(16.0 \%)$ & $21(84.0 \%)$ & & \\
\hline $21-25$ & $29(38.7 \%)$ & $46(61.3 \%)$ & & \\
\hline $26-30$ & $26(40.6 \%)$ & $38(59.4 \%)$ & 9.120 & 0.58 \\
\hline $31-35$ & $8(40.0 \%)$ & $12(60.0 \%)$ & & \\
\hline $36-40$ & $2(12.5 \%)$ & $14(87.5 \%)$ & & \\
\hline \multicolumn{5}{|c|}{ Marital status } \\
\hline Single & $5(31.3 \%)$ & $11(68.7 \%)$ & 0.584 & 1.00 \\
\hline Married & $64(65.0 \%)$ & $119(35.0 \%)$ & & \\
\hline Divorced & $0(0.0 \%)$ & $1(100.0 \%)$ & & \\
\hline \multicolumn{5}{|c|}{ Educational level } \\
\hline Nil & $5(22.7 \%)$ & $17(77.3 \%)$ & & \\
\hline Primary & $0(0.0 \%)$ & $17(100.0 \%)$ & & \\
\hline JHS & $7(14.6 \%)$ & $41(85.4 \%)$ & & \\
\hline SHS & $15(29.4 \%)$ & $36(70.6 \%)$ & & \\
\hline Tertiary & $42(67.7 \%)$ & $20(32.3 \%)$ & 49.639 & $0.01 *$ \\
\hline \multicolumn{5}{|c|}{ Religious status } \\
\hline Christian & $33(76.7 \%)$ & $10(23.3 \%)$ & & \\
\hline Muslim & $36(22.9 \%)$ & $121(77.1 \%)$ & 43.259 & $0.01 *$ \\
\hline
\end{tabular}

$(*)=p$ is statistically significant based on chi square analysis Source: Field data, 2019


American Journal of Health, Medicine and Nursing Practice

ISSN 2520-4017 (Online)

Vol.5, Issue 1 No.5, pp 66 - 83, 2020

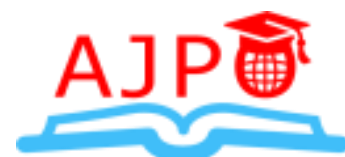

www.ajpojournals.org

\section{Socio-demographics and Knowledge of PCC}

This section looked at the strengths of association between socio-demographic characteristics and knowledge of respondents on PCC. Their statistical significance was determined by their $\mathrm{p}$-values $(\mathrm{p}<0.050)$. When the strength of socio-demographics was associated with knowledge of PCC, educational status (Primary level) $\left(\chi^{2}=45.4 ; p=0.01\right)$ and religion $\left(\chi^{2}=21.3 ; \mathrm{p}=0.01\right)$ were found to show relation and impact on the study statistically. This is indicated in table 6 below.

Table 6: Socio-demographics and Knowledge of PCC

\begin{tabular}{|c|c|c|c|c|c|}
\hline \multirow[t]{2}{*}{ Variable } & \multicolumn{3}{|c|}{ Knowledge } & \multirow[t]{2}{*}{$\chi^{2}$} & \multirow[t]{2}{*}{ P-value } \\
\hline & Poor & Moderate & High & & \\
\hline \multicolumn{6}{|c|}{ Age group } \\
\hline $16-20$ & $14(56.0 \%)$ & $8(32.0 \%)$ & $3(12.0 \%)$ & & \\
\hline $21-25$ & $31(41.3 \%)$ & $27(36.0 \%)$ & $17(22.7 \%)$ & 7.029 & 0.536 \\
\hline $26-30$ & $24(37.5 \%)$ & $19(29.7 \%)$ & $21(32.8 \%)$ & & \\
\hline $31-35$ & $8(40.0 \%)$ & $9(45.0 \%)$ & $3(15.0 \%)$ & & \\
\hline $36-40$ & $8(50.0 \%)$ & $5(31.3 \%)$ & $3(18.7)$ & & \\
\hline \multicolumn{6}{|c|}{ Marital status } \\
\hline Single & $7(43.7 \%)$ & $5(31.3 \%)$ & $4(25 \%)$ & 1.591 & 1.00 \\
\hline Married & $77(42.1 \%)$ & $63(34.4 \%)$ & $45(23.5 \%)$ & & \\
\hline Divorced & $1(100.0 \%)$ & $0(0.0 \%)$ & $0(0.0 \%)$ & & \\
\hline \multicolumn{6}{|c|}{ Educational level } \\
\hline Nil & $15(68.2 \%)$ & $5(22.7 \%)$ & $2(9.1 \%)$ & & \\
\hline Primary & $13(76.5 \%)$ & $3(17.6 \%)$ & $1(5.9 \%)$ & & \\
\hline JHS & $27(56.3 \%)$ & $1531.3 \%$ & $6(12.5 \%)$ & & \\
\hline SHS & $23(45.1 \%)$ & $16(31.4 \%)$ & $12(23.5 \%)$ & & \\
\hline Tertiary & $7(11.3 \%)$ & $29(46.8 \%)$ & $26(41.9 \%)$ & 45.429 & $0.01 *$ \\
\hline \multicolumn{6}{|c|}{ Religious status } \\
\hline Christian & $7(16.3 \%)$ & $16(37.2 \%)$ & $20(46.5 \%)$ & & \\
\hline Muslim & $78(49.7 \%)$ & $52(33.1 \%)$ & $27(17.2 \%)$ & 21.371 & $0.01 *$ \\
\hline
\end{tabular}

$(*)=p$ is statistically significant based on chi square analysis Source: Field data, 2019

\section{Socio-demographic characteristics and Attitude of respondents}

Table 7 below discussed the relationship between independent and dependent variables. When the socio-demographic characteristics were paired in association with overall attitude of respondents, the data gathered shows Religion (Christianity) $\left(\chi^{2}=4.12 ; p=0.04\right)$ had a statistical relation with attitudes. More so, none of the independent variables had a statistical association with practices on PCC. 
American Journal of Health, Medicine and Nursing Practice

ISSN 2520-4017 (Online)

Vol.5, Issue 1 No.5, pp 66 - 83, 2020

www.ajpojournals.org

Table 7: Socio-demographics and Attitude

\begin{tabular}{|c|c|c|c|c|}
\hline \multirow{2}{*}{ Background information } & \multicolumn{2}{|c|}{ Overall Attitude } & \multirow{2}{*}{$\chi^{2}$} & \multirow{2}{*}{ P-value } \\
\hline & $\begin{array}{c}\text { Positive }(\mathrm{N}=40) \\
(100 \%)\end{array}$ & $\begin{array}{c}\text { Negative }(\mathrm{N}=160) \\
(100 \%)\end{array}$ & & \\
\hline \multicolumn{5}{|l|}{ Age group } \\
\hline $16-20$ & $8(20.0 \%)$ & $17(10.6 \%)$ & & \\
\hline $21-25$ & $12(30.0 \%)$ & $63(39.4 \%)$ & 3.470 & 0.428 \\
\hline $26-30$ & $7(17.5 \%)$ & $57(35.6 \%)$ & & \\
\hline $31-35$ & $7(17.5 \%)$ & $13(8.1 \%)$ & & \\
\hline $36-40$ & $6(15.0 \%)$ & $10(6.3 \%)$ & & \\
\hline \multicolumn{5}{|l|}{ Marital status } \\
\hline Single & $9(22.5 \%)$ & $52(32.5 \%)$ & & \\
\hline Married & $30(75.0 \%)$ & $107(66.9 \%)$ & 1.680 & 0.637 \\
\hline Divorced & $1(2.5 \%)$ & $1(0.6 \%)$ & & \\
\hline \multicolumn{5}{|l|}{ Educational level } \\
\hline Nil & $6(15.0 \%)$ & $16(10.0 \%)$ & & \\
\hline Primary & $8(20.0 \%)$ & $9(5.6 \%)$ & & \\
\hline JHS & $9(22.5 \%)$ & $39(24.4 \%)$ & & \\
\hline SHS & $10(25.0 \%)$ & $41(25.6 \%)$ & & \\
\hline Tertiary & $7(17.5 \%)$ & $55(34.4 \%)$ & 6.882 & 0.104 \\
\hline \multicolumn{5}{|l|}{ Religious status } \\
\hline Christian & $13(32.5 \%)$ & $30(18.8 \%)$ & & \\
\hline Muslim & $27(67.5 \%)$ & $130(81.2 \%)$ & 4.123 & $0.042 *$ \\
\hline
\end{tabular}

$(*)=p$ is statistically significant based on chi square analysis Source: Field data, 2019

\section{DISCUSSION}

This study assessed the awareness, knowledge, attitude and practice among women attending antenatal clinic at Tamale West Hospital in Ghana as far as preconception care services are concerned. The awareness level of the study participants on preconception care was analyzed. In affirming the findings of this study that $34.5 \%$ of the respondents had low level of awareness, a study's report showed low levels of awareness among men and women on preconception health. ${ }^{[10]}$ However, this study was contradicted in a report that indicated that females had a higher awareness level than the males in a research conducted on undergraduate students. ${ }^{[11]}$ Notwithstanding, in Nigeria, it has been indicated that $43.1 \%$ of respondents were aware of preconception care in a scientific investigation conducted in that country. ${ }^{[22]}$

Results from this study further showed that the main source of awareness was from the health facility $(20.5 \%)$. This validated the findings that most of the participants who sought preconception care, heard about it during their ANC sessions. ${ }^{[2]}$ In support of this assertion, study participants 
showed a strong preference for obtaining information about preconception healthcare from their personal physician instead of obtaining information from the Internet. ${ }^{[23]}$ However, there was an association between the educational status (Tertiary level) $\left(\chi^{2}=49.6 ; p=0.01\right)$ and religious affiliation (Muslim) $\left(\chi^{2}=43.3 ; \mathrm{p}=0.01\right)$ of the respondents on awareness of preconception care. When the age group was cross-tabulated with awareness, the results showed no statistical significance between the two variables $\left(\chi^{2}=9.1 ; p=0.58\right)$.

When the participants' level of knowledge on preconception care was assessed, $42.5 \%$ and $23.5 \%$ had poor and high knowledge levels respectively. Poor knowledge was acknowledged in other studies $^{[22,24,14]}$ which supports this study's findings. Other studies in Nigeria and among MexicanAmericans respectively, reported that participants have high levels of knowledge on the subject matter ${ }^{[17,12,2]}$ Educational status of respondents (Tertiary level) $\left(\chi^{2}=45.4 ; p=0.01\right)$ and religious affiliation (Muslim) $\left(\chi^{2}=21.3 ; p=0.01\right)$ were found to influence knowledge statistically.

In terms of attitude, 96 (48.0\%) of the respondents strongly agreed that it was very important for every woman to receive preconception care before conception takes place. Reports from other studies affirm this study by indicating that more than one-third of their respondents showed positive attitudes towards preconception care. ${ }^{[\mathbf{9 , 1 7 ]}}$ More so, this statement is in line with a study that claimed that most of the respondents in that study agreed that it was important to receive preconception care prior to pregnancy. ${ }^{[15]}$ Another $67.5 \%$ also agreed that preconception care was important in the reproductive years. Other authors also indicated that it was important for all women of child bearing age to receive preconception care. ${ }^{[25,1]}$ When the regression analysis was done, only Muslim $\left(\chi^{2}=4.12 ; p=0.04\right)$ statistically impacted on the attitude.

In terms of practice, findings from this study revealed that only $30(15 \%)$ of respondents visited the health facility for PCC services. This is conviction that PCC services is rendered in the Tamale West Hospital at the antenatal clinic. Interestingly, most of them wanted to seek PCC (interconception care) next time which is consistent with findings from other studies ${ }^{\left[{ }^{[9,12}\right]}$ Furthermore, $63.5 \%$ of the respondents in the present study undertake exercises during the week. This was in support of other report that indicated that majority of respondents took to exercising, maintaining good nutrition, and taking well balanced diet. ${ }^{[2]}$

This study showed a lower percentage $34.0 \%$ (68/200) of respondents who used folic acid before pregnancy. This was in line with other studies that supported women of child bearing age to take vitamins, including folic acid, within the first trimester of their pregnancy. ${ }^{[2,6,13]}$ However, findings of this study contradicts the other studies that reported that women in their reproductive age have inadequate knowledge on folic acid supplementation. ${ }^{[4,26,16]}$

\section{CONCLUSION}

Pregnant women who attend ANC at Tamale West Hospital tended to have low level of awareness and poor knowledge, they have negative attitude towards preconception care services and seldom practice preconception care.

There is the need for health care authorities to intensify awareness and implement preconception care policies. 


\section{RECOMMENDATIONS:}

1. The present study demonstrated that there was a need to create awareness which can also increase the knowledge and practices of reproductive age women or couples. Hence, there is the need for health authorities to put together comprehensive preconception care policies for health institutions to abide by..

2. Nursing researchers need to assist in the development of strategies to integrate preconception care interventions into the existing maternal and child health care programmes.

3. Organization of outreaches to the communities to create awareness on the subject and to provide education on the importance of practicing preconception care.

\section{REFERENCES}

1. World Health Organization. (2013). Meeting to develop a global consensus on preconception care to reduce maternal and childhood mortality and morbidity: February 2012 meeting report. Geneva: WHO.

2. Olowokere, A. E., Komolafe, A., \& Owofadeju, C. (2015). Awareness, knowledge and uptake of preconception care among women in Ife Central Local Government Area of Osun State, Nigeria. Journal of Community Medicine and Primary Health Care, 27(2): 83-92.

3. Dean, S., Rudan, I., Althabe, F., Girard, A. W., Howson, C., Langer, A., ..., \& Venkatraman, C. M. (2013). Setting research priorities for preconception care in low-and middle-income countries: Aiming to reduce maternal and child mortality and morbidity. PLoS Medicine, 10(9): e1001508.

4. Gautan, P., \& Dhakal, R. (2016). Knowledge on preconception care among reproductive age women. Saudi J Med Pharm Sci, 2(1): 6.

5. Mason, E., Chandra-Mouli, V., Baltag, V., Christiansen, C., Lassi, Z. S., \& Bhutta, Z. A. (2014). Preconception care: Advancing from 'important to do and can be done to is being done and is making a difference'. Reproductive Health, 11(3): S8.

6. Williams, J. L., Abelman, S. M., Fassett, E. M., Stone, C. E., Petrini, J. R., Damus, K., \& Mulinare, J. (2006). Health care provider knowledge and practices regarding folic acid, United States, 2002-2003. Maternal and Child Health Journal, 10(1): 67-72.

7. Giri, K., \& Gautam, S. (2018). Knowledge on preconception care among reproductive aged women in Kaski District, Nepal. Janapriya Journal of Interdisciplinary Studies, 7(1): 46-56.

8. Ayalew, Y., Mulat, A., Dile, M., \& Simegn, A. (2017). Women's knowledge and associated factors in preconception care in Adet, West Gojjam, Northwest Ethiopia: A community based cross-sectional study. Reproductive Health, 14(1), 15. 
9. Ahmed, K. M., Elbashir, I. M. H., Mohamed, S., Saeed, A. K. M., \& Alawad, A. A. M. (2015). Knowledge, attitude and practice of preconception care among Sudanese women in reproductive age about rheumatic heart disease at Alshaab and Ahmad Gassim hospitals 20142015 in Sudan. Basic Res. J. Med. Clin. Sci., 4(7): 5.

10. Mitchell, E. W., Levis, D. M., \& Prue, C. E. (2012). Preconception health: Awareness, planning, and communication among a sample of US men and women. Maternal and Child Health Journal, 16(1): 31-39.

11. Delgado, C. E. (2008). Undergraduate student awareness of issues related to preconception health and pregnancy. Maternal and Child Health Journal, 12(6): 774-782.

12. Coonrod, D. V., Bruce, N. C., Malcolm, T. D., Drachman, D., \& Frey, K. A. (2009). Knowledge and attitudes regarding preconception care in a predominantly low-income Mexican-American population. American Journal of Obstetrics and Gynecology, 200(6): 686e1.

13. Wilton, D. C., \& Foureur, M. J. (2010). A survey of folic acid use in primigravid women. Women and Birth, 23(2): 67-73. Retrieved 6th August, 2019 from https://scholar.google.com/scholar.

14. Nepali, G., \& Sapkota, S. D. (2017). Knowledge and practice regarding preconception care among antenatal mothers. International Journal of Perceptions in Public Health, 1(4): 224227.

15. Crusenberry, K. J. (2016). An online study of undergraduates' knowledge, awareness, and attitudes of preconception care.

16. Krishnan, G. G., Joseph, J., \& Maheswari, B. (2016). Effect of structured West program on knowledge and attitude regarding preconception care among adolescent girls. IJAR, 2(4): 435439.

17. Bayrami, R., Ebrahimipour, H., Ebrahimi, M., Forootani, M., \& Najafzadeh, B. (2013). Health care providers' knowledge, attitude and practice regarding pre-conception care. Journal of Research and Health, 3(4): 519-526.

18. Klein, J., Boyle, J. A., Kirkham, R., Connors, C., Whitbread, C., Oats, J., ..., \& Shaw, J. (2017). Preconception care for women with type 2 diabetes mellitus: A mixed-methods study of provider knowledge and practice. Diabetes Research and Clinical Practice, 129: 105-115.

19. van Voorst, S., Plasschaert, S., de Jong-Potjer, L., Steegers, E., \& Denktaş, S. (2016). Current practice of preconception care by primary caregivers in the Netherlands. The European Journal of Contraception \& Reproductive Health Care, 21(3): 251-258. 
20. Sattarzadeh, N., Farshbaf-Khalili, A., \& Khari, E. (2017). Socio-demographic predictors of midwives' knowledge and practice regarding preconception care. International Journal of Women's Health and Reproduction Sciences, 5(3): 212-217.

21. Temel, S., van Voorst, S. F., Jack, B. W., Denktaş, S., \& Steegers, E. A. (2013). Evidencebased preconceptional lifestyle interventions. Epidemiologic reviews, 36(1): 19-30.

22. Ezegwui, H. U., Dim, C., Dim, N., \& Ikeme, A. C. (2008). Preconception care in South Eastern Nigeria. Journal of Obstetrics and Gynaecology, 28(8): 765-768.

23. Frey, K. A., \& Files, J. A. (2006). Preconception healthcare: what women know and believe. Maternal and Child Health Journal, 10(1), 73-77.

24. Fadia, M., Azza Refaat, T., \& Emam, E. (2012). Awareness of primary health care providers in Elminia Governorate about preconception care, Egipt. El-Minia Medical Bulletin, 23(1): 14.

25. Phipps, E. (2016). Using school nurses to deliver preconception health education: A call to action. British Journal of School Nursing, 11(5): 243-245.

26. Abu-Hammad, T., Dreiher, J., Vardy, D. A., \& Cohen, A. D. (2008). Physicians' knowledge and attitudes regarding periconceptional folic acid supplementation: A survey in Southern Israel. Medical Science Monitor, 14(5), CR262-CR267. 